\title{
Discrimination and Genetic Diversity of Cephalotaxus Accessions Using AFLP Markers
}

\author{
Donglin Zhang \\ Landscape Horticulture Program, Department of Biosystems Science and Engineering, University of \\ Maine, Orono, ME 04469-5722 \\ Michael A. Dirr and Robert A. Price ${ }^{1}$ \\ Department of Horticulture, University of Georgia, Athens, GA 30602
}

AdDitional INDEX wORDs. DNA, markers, taxonomy, PCR, phenogram, cultivar

\begin{abstract}
Cephalotaxus Sieb. and Zucc. (plum yew) species and cultivars have become popular because of their sun and shade tolerance, resistance to deer browsing, disease and insect tolerance, and cold and heat adaptability. Unfortunately, the nomenclature and classification in the literature and nursery trade are confusing due to their extreme similarity in morphology. In this study, amplified fragment-length polymorphism (AFLP) markers were used to discriminate taxa and evaluate genetic differences among 90 Cephalotaxus accessions. A total of 403 useful markers between 75 and 500 base pairs (bps) was generated from three primer-pair combinations. Cluster analysis showed that the 90 accessions can be classified as four species, C. oliveri Mast., C. fortunei Hooker, C. harringtonia (Forbes) Koch., and C. $\times$ sinensis (a hybrid species); four varieties, $C$. fortunei var. alpina $\mathrm{Li}, C$. harringtonia var. koreana (Nakai) Rehd., C. harringtonia var. nana (Nakai) Hornibr., and C. harringtonia var. wilsoniana (Hayata) Kitamura; and eight cultivars. Suggested names are provided for mislabeled or misidentified taxa. The Cephalotaxus AFLP data serve as a guide to researchers and growers for identification and genetic differences of a taxon, and a model to establish a cultivar library against which later introductions or problematic collections can be cross-referenced.
\end{abstract}

Cephalotaxus (plum yew) taxa are native to the southern Asia and the Himalayas (China, Japan, and Korea) and were introduced to Europe, America, and Australia in the early 1800s and cultivated as landscape plants. Morphologically, plum yews are normally dioecious and infrequently monoecious. Throughout cultivated history, branch sports (chimeras) or seedling selections have originated throughout the world. Taxonomically, Cephalotaxus is a small genus with four to nine species, depending on the authority (Dallimore and Jackson, 1967; Fu, 1984; Krüssmann, 1985; Mabberley, 1993; Rushforth, 1987; Silba, 1984). Fu (1984) recognized five species as endemic to China, three species with distribution in China and adjacent countries, and one species, $C$. harringtonia, as native to Japan and Korea. Cephalotaxus harringtonia (Forbes) Koch was introduced to England in 1829 and to the United States in 1830. In the 1990s, the plants became popular because of their sun and shade tolerance [can substitute for junipers (Juniperus L. sp.)], resistance to deer browsing, tolerance to diseases and insects, and cold and heat adaptability (Dirr, 1990, 1992; Hillier Nurseries, 1995; Tripp, 1994).

Cephalotaxus harringtonia 'Prostrata', a low growing form, was awarded the Gold Medal by the Georgia Green Industry Association in 1994 (Harlass, 1994). Unfortunately, the nomenclature and classification in the literature and nursery trade are very confusing due to morphological similarities among species and the complicated history of Cephalotaxus taxonomy. During their 170-year period of cultivation in the western hemisphere, many new cultivars were introduced by growers around the world

Received for publication 21 June 1999. Accepted for publication 20 Mar. 2000 Maine Agricultural and Forest Experiment Station Publication 2404. The marker portion of this research was conducted in the lab of Stephen Kresovich in Griffin, Georgia. We thank Stephen Kresovich, Sharon Mitchell, Doug Butts, and Vickie Waters for technical support and assistance. Also, thanks extend to those who provided plant materials. The cost of publishing this paper was defrayed in part by the payment of page charges. Under postal regulations, this paper therefore must be hereby marked advertisement solely to indicate this fact.

${ }^{1}$ Department of Botany.
(Tripp, 1994). Cephalotaxus taxa with the same names are often not morphologically similar and morphologically similar plants do not necessarily bear the same name. Furthermore, some new cultivars are introduced into the trade without descriptions and origination. It has been difficult to classify the various taxa by morphological characters (Dirr, 1990), but modern molecular fingerprinting techniques could aid classification.

Deoxyribonucleic acid (DNA) fingerprinting techniques are preferred methods for identifying cultivars or genotypes and investigating the genetic variability within species because DNA markers are not influenced by environmental or cultural factors, such as geographical location, microclimate, and nutrition (Nybom, 1994; Staub and Meglic, 1993). The rapid, accurate information derived from DNA can be used to distinguish closely related plants, especially a morphologically homogenous group of plants (Nybom, 1994). Currently, several DNA fingerprinting techniques are available. The widely used techniques are restriction fragment length polymorphism (RFLP) and the polymerase chain reaction (PCR)-based random amplified polymorphic DNA (RAPD). RFLPs have been used to investigate genetic diversity in cultivated plants (Paul et al., 1997) and their wild relatives (Miller and Tanksley, 1990; Wang et al., 1992). Hubbard et al. (1992) successfully applied RFLP techniques for identification of rose (Rosa L. sp.) cultivars. However, the RFLP assay is more expensive because it requires large amounts of high quality DNA, frequently employs radioactive isotopes for probe labeling, and uses X-ray film for marker detection (Lin et al., 1996; Staub and Meglic, 1993). On the other hand, the RAPD assay is less expensive and overcomes some technical limitations of RFLPs. It has been used for cultivar discrimination (Staub and Meglic, 1993), such as clonal identification in red maple (Acer rubrum L.) (Krahl et al., 1993) and American elm (Ulmus americana L.) (Kamalay and Carey, 1995). Michelmore et al. (1991) reported that RAPD markers were useful in construction of genetic maps and could be used as linkage markers for downy mildew (Bremia lactucae Regel) resistance in lettuce (Lactuca sativa L.). How- 
Table 1. Plant sources for Cephalotaxus accessions and suggested name after AFLP data analysis and morphological comparison $(\boldsymbol{\lambda}=$ male, $\mathbf{+}=$ female, $?=$ unknown).

\begin{tabular}{|c|c|c|}
\hline Accession no. & Plant name ${ }^{\mathrm{z}}$ and source & Suggested name ${ }^{y}$ \\
\hline$\overline{1}$ & + C. drupacea; F. Pokorny's Garden, Athens, Ga. & C. harringtonia \\
\hline 2 & ? C. drupacea (seedling); F.W. Schumacher Inc., Sandwich, Mass. & C. harringtonia \\
\hline 3 & ? C. drupacea; J.C. Raulston Arb., Raleigh, N.C. & C. harringtonia 'Duke Gardens' \\
\hline 4 & ? C. drupacea; Georgia State Arb., Braselton, Ga. & C. harringtonia \\
\hline 5 & $>$ C. fortunei; Arnold Arb., Jamaica Plain, Mass. & C. fortunei \\
\hline 6 & + C. fortunei; R. Ellis' Garden, Aiken, S.C. & C. harringtonia \\
\hline 7 & ? C. fortunei (seedling); R. Ellis' Garden, Aiken, S.C. & C. harringtonia \\
\hline 8 & ? C. fortunei (361046); Edinburgh Bot. Garden, Scotland & C. fortunei \\
\hline 9 & ? C. fortunei (687276); Edinburgh Bot. Garden, Scotland & C. harringtonia \\
\hline 10 & ? C. fortunei (seedling); F.W. Schumacher, Inc., Sandwich, Mass. & C. harringtonia \\
\hline 11 & + C. fortunei (69.16245); Kew Gardens, England & C. harringtonia 'Prostrata' \\
\hline 12 & ? C. fortunei; Nurseries Caroliniana, N.Augusta, S.C. & C. fortunei \\
\hline 13 & ? C. fortunei; Yucca Do Nursery, Waller, Texas & C. fortunei \\
\hline 14 & + C. fortunei 'Grandis'; Hillier Arb., England & C. fortunei 'Grandis' \\
\hline 15 & ? C. fortunei 'Prostrate Spreader'; Hillier Arb., England & C. fortunei 'Prostrate Spreader' \\
\hline 16 & C. harringtonia; Atlanta Bot. Garden, Atlanta, Ga. & C. harringtonia \\
\hline 17 & ? C. harringtonia; Earth Shade Nursery, Warne, N.C. & C. harringtonia 'Prostrata' \\
\hline 18 & ? C. harringtonia; Edinburgh Bot. Garden, Scotland & C. harringtonia \\
\hline 19 & ? C. harringtonia (94-1497A); Edinburgh Bot. Garden, Scotland & C. harringtonia \\
\hline 20 & ? C. harringtonia (tissue culture); J. Frett, Newark, Del. & C. harringtonia \\
\hline 21 & + C. harringtonia ; Kew Gardens, England & C. harringtonia 'Prostrata' \\
\hline 22 & $\nearrow$ C. harringtonia; Univ. Ga. Bot. Garden, Athens, Ga. & C. harringtonia \\
\hline 23 & + C. harringtonia; Univ. Ga. Bot. Garden, Athens, Ga. & C. harringtonia 'Prostrata' \\
\hline 24 & \. harringtonia; Univ. Ga. Campus, Athens, Ga. & C. harringtonia 'Duke Gardens' \\
\hline 25 & $\nearrow$ C. harringtonia 'Augusta Upright'; Natl. Golf Course, Augusta, Ga. & C. harringtonia \\
\hline 26 & ? C. harringtonia 'Dirr Clone'; M. Dirr's Garden, Watkinsville, Ga. & C. harringtonia 'McCorkle' \\
\hline 27 & ? C. harringtonia var. drupacea; Edinburgh Bot. Garden, Scotland & C. harringtonia 'Prostrata' \\
\hline 28 & $>$ C. harringtonia var. drupacea (1978); Hillier Arb., England & C. harringtonia \\
\hline 29 & ? C. harringtonia var. drupacea (1980); Hillier Arb., England & C. harringtonia \\
\hline 30 & + C. harringtonia var. drupacea; Kew Gardens, England & C. harringtonia 'Prostrata' \\
\hline 31 & + C. harringtonia var. drupacea; Overlook Nursery, Mobile, Ala. & C. harringtonia 'Prostrata' \\
\hline 32 & ? C. harringtonia var. drupacea; Woodlanders Nursery, Aiken, S.C. & C. harringtonia 'Prostrata' \\
\hline 33 & ? C. harringtonia var. drupacea; Yucca Do Nursery, Waller, Texas & C. harringtonia \\
\hline 34 & ? C. harringtonia 'Duke Gardens'; Yucca Do Nursery, Waller, Texas & C. harringtonia 'Duke Gardens' \\
\hline 35 & ? C. harringtonia 'Mary Flemming'; Yucca Do Nursery, Waller, Texas & C. harringtonia 'Prostrata' \\
\hline 36 & $>$ C. harringtonia 'Prostrate Form'; Yucca Do Nursery, Waller, Texas & C. harringtonia 'Prostrata' \\
\hline 37 & ? C. harringtonia 'Duke Gardens'; Bernheim Arb., Clermont, Ky. & C. harringtonia 'Duke Gardens' \\
\hline 38 & ? C. harringtonia 'Duke Gardens'; Duke Gardens, Durham, N.C. & C. harringtonia 'Duke Gardens' \\
\hline 39 & ? C. harringtonia 'Fastigiata'; Arnold Arb., Jamaica Plain, Mass & C. harringtonia 'Fastigiata' \\
\hline 40 & ? C. harringtonia 'Fastigiata'; Edinburgh Bot. Garden, Scotland & C. harringtonia 'Fastigiata' \\
\hline 41 & ? C. harringtonia 'Fastigiata'; Hillier Arb., England & C. harringtonia 'Fastigiata' \\
\hline 42 & ? C. harringtonia var. fastigiata; Kew Gardens, England & C. harringtonia 'Duke Gardens' \\
\hline 43 & ? C. harringtonia 'Fastigiata'; McCorkle Nurseries, Dearing, Ga. & C. harringtonia 'Fastigiata' \\
\hline 44 & ? C. harringtonia 'Fastigiata'; Overlook Nursery, Mobile, Ala. & C. harringtonia 'Fastigiata' \\
\hline 45 & ? C. harringtonia 'Fastigiata'; Univ. Ga. Bot. Garden, Athens, Ga. & C. harringtonia 'Duke Gardens' \\
\hline 46 & ? C. harringtonia var. fastigiata; Yucca Do Nursery, Waller, Texas & C. harringtonia 'Fastigiata' \\
\hline 47 & C. harringtonia; Nurseries Caroliniana, N. Augusta, S.C. & C. harringtonia \\
\hline 48 & ? C. harringtonia 'Fritz Huber'; Yucca Do Nursery, Waller, Texas & C. harringtonia 'Prostrata' \\
\hline 49 & ? C. harringtonia 'Gimborn's Pillow'; Barncroft Nurseries, England & C. harringtonia 'Prostrata' \\
\hline 50 & ? C. harringtonia ‘Glasnevin'; Natl. Bot. Garden, Ireland & C. harringtonia var. nana \\
\hline 51 & ? C. harringtonia 'Gnome'; Hillier Arb., England & C. harringtonia 'Duke Gardens' \\
\hline 52 & ? C. harringtonia 'Goodyear'; Goodyear Garden, Aiken, S.C. & C. harringtonia 'Goodyear' \\
\hline 53 & ? C. harringtonia 'H.W. Sargent'; J.C. Raulston Arb., Raleigh, N.C. & C. harringtonia 'Prostrata' \\
\hline 54 & ? C. harringtonia 'Long Leaf Form'; Hill Nursery, Commerce, Ga. & C. harringtonia 'Prostrata' \\
\hline 55 & ? C. harringtonia ‘Short Leaf Form’; Hill Nursery, Commerce, Ga. & C. harringtonia 'Duke Gardens' \\
\hline 56 & ? C. harringtonia 'Korean Gold'; Atlanta Bot. Garden, Atlanta, Ga & C. harringtonia 'Fastigiata' \\
\hline 57 & ? C. harringtonia 'Drupacea'; McCorkle Nurseries, Dearing, Ga. & C. harringtonia 'McCorkle' \\
\hline 58 & $>$ C. harringtonia var. nana; Arnold Arboretum, Jamaica Plain, Mass. & C. harringtonia var. nana \\
\hline
\end{tabular}


Table 1. Continued $(\boldsymbol{\nearrow}=$ male, $\boldsymbol{+}=$ female, $?=$ unknown $)$.

\begin{tabular}{|c|c|c|}
\hline Accession no. & Plant name ${ }^{\mathrm{z}}$ and source & Suggested name ${ }^{y}$ \\
\hline$\overline{59}$ & ? C. harringtonia var. nana; Kew Gardens, England & C. harringtonia var. nana \\
\hline 60 & ? C. harringtonia 'Ogon'; Atlanta Botanical Garden, Atlanta, Ga. & C. harringtonia 'Fastigiata' \\
\hline 61 & $\rtimes$ C. harringtonia 'Pedunculata'; Arnold Arb., Jamaica Plain, Mass. & C. harringtonia \\
\hline 62 & \. harringtonia 'Prostrata'; Arnold Arb., Jamaica Plain, Mass. & C. harringtonia 'Prostrata' \\
\hline 63 & 入 C. harringtonia 'Prostrata'; Brooklyn Bot. Garden, Brooklyn, N.Y. & C. harringtonia 'Prostrata' \\
\hline 64 & ? C. harringtonia 'Prostrata'; M. Dirr's Garden, Watkinsville, Ga. & C. harringtonia 'Prostrata' \\
\hline 65 & ? C. harringtonia 'Prostrata'; McCorkle Nurseries, Dearing, Ga. & C. harringtonia 'Prostrata' \\
\hline 66 & ? C. harringtonia 'Ridge Spring'; Watson's Garden, Ridge Spring, S.C. & C. harringtonia 'Ridge Spring' \\
\hline 67 & ? C. harringtonia 'Short Form'; County Line Nursery, Byron, Ga. & C. harringtonia 'Prostrata' \\
\hline 68 & + C. harringtonia var. sinensis; Kew Gardens, England & C. harringtonia \\
\hline 69 & ? C. harringtonia 'Tall Form'; County Line Nursery, Byron, Ga. & C. harringtonia 'Prostrata' \\
\hline 70 & ? C. harringtonia 'Weeping'; Bransford Road, Augusta, Ga. & C. harringtonia \\
\hline 71 & + C. koreana ; Arnold Arb., Jamaica Plain, Mass. & C. harringtonia var. koreana \\
\hline 72 & ? C. koreana; Atlanta Bot. Garden, Atlanta, Ga. & C. harringtonia var. koreana \\
\hline 73 & $\lambda$ C. koreana (75.20552); Kew Gardens, England & C. harringtonia var. koreana \\
\hline 74 & ? C. koreana; J.C. Raulston Arb., Raleigh, N.C. & C. harringtonia var. koreana \\
\hline 75 & ? C. koreana; Nurseries Caroliniana, N. Augusta, S.C. & C. harringtonia var. koreana \\
\hline 76 & C. koreana; Yucca Do Nursery, Waller, Texas & C. harringtonia var. koreana \\
\hline 77 & ? C. oliveri ; Piroche Plants, Pitt Meadows, BC, Canada & C. oliveri \\
\hline 78 & ? C. sinensis (hybrid); Arnold Arb., Jamaica Plain, Mass. & C. $\times$ sinensis \\
\hline 79 & $>$ C. sinensis; Arnold Arb., Jamaica Plain, Mass. & C. $\times$ sinensis \\
\hline 80 & + C. sinensis; Atlanta Bot. Garden, Atlanta, Ga. & C. $\times$ sinensis \\
\hline 81 & ? C. sinensis; Edinburgh Bot. Garden, Scotland & C. $\times$ sinensis \\
\hline 82 & ? C. sinensis; Nurseries Caroliniana, N. Augusta, S.C. & C. $\times$ sinensis \\
\hline 83 & C. sinensis; Yucca Do Nursery, Waller, Texas & C. $\times$ sinensis \\
\hline 84 & ? C. sinensis 'Dogwoodhills'; Yucca Do Nursery, Waller, Texas & C. harringtonia \\
\hline 85 & ? C. wilsoniana (93-3497B); Edinburgh Bot. Garden, Scotland & C. harringtonia var. wilsoniana \\
\hline 86 & ? C. wilsoniana (93-4074B); Edinburgh Bot. Garden, Scotland & C. harringtonia var. wilsoniana \\
\hline 87 & ? C. wilsoniana (93-3497D); Edinburgh Bot. Garden, Scotland & C. harringtonia var. wilsoniana \\
\hline 88 & ? C. fortunei var. alpina; Atlanta Bot. Garden, Atlanta, Ga. & C. fortunei var. alpina \\
\hline 89 & ? C. harringtonia; Univ. W. Australia, Perth, Australia & C. harringtonia \\
\hline 90 & ? C. harringtonia 'Sea Island'; The Cloisters, Sea Island, Ga. & C. harringtonia \\
\hline
\end{tabular}

zPlant names were not verified or identified by authors and were listed as they were labeled.

${ }^{y}$ Suggested name after AFLP analysis.

ever, RAPD analysis is sensitive to experimental conditions (primer selections, magnesium concentration, and PCR conditions) and can be subject to low reproducibility if the DNA concentration is below a threshold value or if amplification conditions are alternated (Lin et al., 1996).

Amplified fragment length polymorphism (AFLP) was developed by Kengene in Wageningen, The Netherlands (Vos et al., 1995; Zabeau and Vos, 1993); a combination of RFLP analysis and PCR, which results in highly informative fingerprints. Compared with RFLP or RAPD markers, analyzing AFLPs is the most useful, reliable, and promising molecular marker technique for genotypic comparisons within species (Becker et al., 1995; Lin et al., 1996; Meksem et al., 1995). Zhang (1997) reported 99.9\% reproducibility among three replications of 27 bermudagrass [Cynodon dactylon (L.) Pers.] genotypes. He also concluded that the AFLP technique not only had high reproducibility and revealed a high frequency of polymorphism, but also could be used for cultivar identification and protection. The present study uses AFLPs to determine the genetic distinctness of Cephalotaxus taxa.

\section{Materials and Methods}

Plant materials. In this study, 90 accessions of Cephalotaxus were collected and grown in environmentally controlled greenhouses, outdoor lath areas, and field trials at the University of Georgia, Athens (Table 1).

DNa EXTRaction. Total genomic DNA was isolated from leaves following the acidic extraction protocol (modified from Guillemaut and Marechal-Drouard, 1992) which can be summarized as follows. One gram of fresh mature leaf tissue $(0.5 \mathrm{~g}$ for young and silica gel dried leaves) was ground in liquid nitrogen, then mixed with $10 \mathrm{~mL}$ of extraction buffer $(100 \mathrm{~mm} \mathrm{NaOAc}$ at pH 4.8, 50 mм EDTA, $500 \mathrm{~mm} \mathrm{NaCl}, 2 \%$ polyvinylpyrrolidone (PVP), $1.4 \%$ sodium dodecyl sulfate (SDS), $50 \mathrm{~mm}$ cysteine, and pure sodium hydroxide beads to adjust $\mathrm{pH}$ to 5.5) and incubated at $65{ }^{\circ} \mathrm{C}$ for $10 \mathrm{~min}$ with occasional swirling. Samples were centrifuged at $5000 \mathrm{~g}_{\mathrm{n}}$ for $10 \mathrm{~min}$. The supernatant was decanted into a new tube and $4 \mathrm{~mL} 3 \mathrm{~m}$ potassium acetate at $\mathrm{pH} 5.4$ was added. Tubes were incubated in an ice-water bath for at least 30 min, centrifuged at $5000 g_{\mathrm{n}}$ for $10 \mathrm{~min}$ at $4{ }^{\circ} \mathrm{C}$ and, the supernatant was decanted into a new tube. One volume of pure ice-cold isopropanol was added and the tubes were placed at $-20^{\circ} \mathrm{C}$ for 1 to $2 \mathrm{~h}$, then centrifuged at $5000 \mathrm{~g}$ for $10 \mathrm{~min}$ at $4{ }^{\circ} \mathrm{C}$. The supernatant was discarded and the pellet was dried for $24 \mathrm{~h}$, then redissolved in 500 to $600 \mu \mathrm{L}$ TE buffer ( $10 \mathrm{~mm}$ Tris, 1 mm EDTA) at $\mathrm{pH}$ 8.0. DNAse-free RNAse was added to the dissolved pellet at $8 \mu \mathrm{g} \cdot \mathrm{mL}^{-1}$ and incubated at $37^{\circ} \mathrm{C}$ for $39 \mathrm{~min}$ or more. The 
Table 2. Oligonucleotide adaptors and primers used for AFLP analysis of Cephalotaxus accessions.

\begin{tabular}{cc}
\hline \hline Adaptor or primer & Oligonucleotide \\
\hline EcoRI adaptors & CTCGTAGACTGCGTACC \\
MseI adaptors & CATCTGACGCATGGTTAA \\
& GACGATGAGTCCTGAG \\
AFLP primers & TACTCAGGACTCAT \\
EcoRI +1 & AGACTGCGTACC + AATTC + A \\
MseI +1 & GATGAGTCCTGAG + TAA + C \\
EcoRI +3 & GACTGCGTACC + AATTC + ACT \\
& GACTGCGTACC + AATTC + ACG \\
& GACTGCGTACC + AATTC + AGC \\
MseI +3 & GATGAGTCCTGAG + TAA + CTC \\
\hline
\end{tabular}

solution was transferred to $1.5 \mathrm{~mL}$ tubes, then $500 \mu \mathrm{L}$ phenol at $\mathrm{pH} 8.0$ was added. The sample was mixed and centrifuged in a microcentrifuge at $5000 g_{\mathrm{n}}$ for 3 to $5 \mathrm{~min}$. The upper layer was transferred to another tube and $500 \mu \mathrm{L}$ of pure ice-cold isopropanol was added. DNA was pelleted by centrifugation, then stored in a freezer at $-20{ }^{\circ} \mathrm{C}$ in deionized distilled water.

All isolated DNAs were quantified using a DNA Fluorometer (Hoefer Scientific Instruments, San Francisco, Calif.). The original DNA concentrations were between 107 and $574 \mu \mathrm{g} \cdot \mathrm{mL}^{-1}$. A DNA stock solution of $20 \mu \mathrm{L}$ at $100 \mu \mathrm{g} \cdot \mathrm{mL}^{-1}$ was used for the AFLP experiment.

Aflp Procedure. Perkin Elmer (Foster City, Calif.) Large Plant Genome Kit and Small Plant Genome Kit were purchased to conduct the research. Amplified fragment length polymorphism reactions were conducted as recommended by the Perkin Elmer AFLP Plant Mapping Protocol (PE Applied Biosystems, 1996) except for the following modifications.

1) Restriction-ligation reactions: Master Mix I for digestion of template DNA and Master Mix II for AFLP adaptor ligation to target sequences were prepared separately, then combined in a single tube.

2) Preselective amplifications of target sequences: Preselective primer pairs were primers complementary to the DNA sequences of the AFLP adaptor oligonucleotides (Table 2).

Polymerase chain reactions (PCRs) were performed on the GeneAmp PCR System 9600 (Perkin-Elmer, Norwalk, Conn.) as follows: one cycle at $72^{\circ} \mathrm{C}$ for $2 \mathrm{~min}$, then 20 cycles at $94^{\circ} \mathrm{C}$ for $1 \mathrm{~s}, 56{ }^{\circ} \mathrm{C}$ for $30 \mathrm{~s}$, and $72{ }^{\circ} \mathrm{C}$ for $2 \mathrm{~min}$. The preselective PCR products $(10 \mu \mathrm{L}$ for each sample) were verified by electrophoresis on an $1.5 \%$ agarose gel stained with ethidium bromide. Smears of the PCR products from 100 to 1500 bps were clearly visible.

3) Selective amplification: Initially, four accessions $(C$. harringtonia, $C$. harringtonia 'Duke Gardens', $C$. harringtonia 'Fastigiata', and C. harringtonia 'Prostrata') were tested with 32 primer combinations including 16 from a Perkin Elmer Large Plant Genome Kit and 16 from a Small Plant Genome Kit. Based on the results obtained, such as band patterns and average band numbers, three of these 32 combinations were selected and used against all 90 Cephalotaxus samples. The three primer pairs were MseI adaptor sequence plus CTC combining with EcoRI adaptor sequence plus ACT, ACG, and AGC (Table 2). In all reactions, only EcoRI selective primers were labeled with a fluorescent dye (Perkin-Elmer, Foster City, Calif.). PCRs were performed on the same machine mentioned above with a touchdown cycle profile as follows: $94^{\circ} \mathrm{C}$ for $2 \mathrm{~min}, 65^{\circ} \mathrm{C}$ for $30 \mathrm{~s}$, and $72{ }^{\circ} \mathrm{C}$ for $2 \mathrm{~min}$, then
$94{ }^{\circ} \mathrm{C}$ for $1 \mathrm{~s}, 64^{\circ} \mathrm{C}\left(-1{ }^{\circ} \mathrm{C} /\right.$ cycle $)$ for $30 \mathrm{~s}$, and $72{ }^{\circ} \mathrm{C}$ for 2 min until reaching the optimal annealing temperature of $56{ }^{\circ} \mathrm{C}$. At this temperature, 27 more cycles were carried out for all EcoRI primers.

4) Multiplex, gel, and electrophoresis conditions: Although single PCRs were performed for each primer combination, the products from all three primer combinations were loaded simultaneously on a $5.0 \%$ long ranger gel [19 acrylamide : 1 bisacrylamide (v/v)] in $1 \times$ TBE buffer $(89 \mathrm{~mm}$ Tris, $89 \mathrm{~mm}$ borate, and 2 mm EDTA). Samples were electrophoresed ( $2500 \mathrm{~V})$ for 4 $\mathrm{h}$ at $48{ }^{\circ} \mathrm{C}$ in $1 \times \mathrm{TBE}$ buffer, on an automated DNA sequencer (model ABI377, Perkin-Elmer, Applied Biosystems) equipped with GeneScan Analysis software (version 2.0.2. Perkin-Elmer, Applied Biosystems). Fragment sizes were calculated automatically using the local Southern sizing algorithms (Elder and Southern, 1987).

5) AFLP data analyses: Combined data files containing sizing data for all DNAs were created using Genotyper (version 1.1, Perkin-Elmer, Applied Biosystems) for each primer combination. The threshold value for fragment detection was 50. Pairwise comparisons were done for all genotypes, and the number of shared fragments for each comparison was calculated with the aid of Mathematica (version 2.2, Wolfram Research, Champaign, Ill.). Relative genetic similarity coefficient $\left(S_{\mathrm{xy}}\right)$ was estimated according to Nei and Li (1979) by Excel (version 6.0, Microsoft). Conversion to genetic distance, $D_{x y}$, was obtained by the following equation: $D_{x y}=1-S_{x y}$ (data not presented) and unweighted pair group method with arithmetic average (UPGMA) and neighbor-joining (NJ) phenograms were derived using molecular evolutionary genetics analysis (MEGA) (Sudhir et al., 1993), numerical taxonomy and multivariate analysis system (NTSYS) (Rohlf, 1993), and phylogeny inference package (PHYLIP) (Felsenstein, 1995).

\section{Results and Discussion}

A total of 403 useful markers between 75 and $500 \mathrm{bps}$ fragment sizes were generated from three primer-pair combinations of 90 Cephalotaxus accessions. The average number of markers for each accession was 208 and each primer-pair combination produced $\approx 70$ useful markers for each taxon (Table 3 ). Little variation $(<10 \%)$ was observed among primer-pair combinations for the number of useful markers except for accessions 16 (157 markers) and 84 (141 markers) (Tables 1 and 3).

Based on all useful AFLP markers, genetic dissimilarity coefficients $\left(D_{x y}\right)$ were calculated (data not presented). Dissimilarity coefficients ranged from 0.0043 to 0.4253 . Both male clones of $C$. harringtonia 'Prostrata' collected from the Arnold Arboretum and Brooklyn Botanical Garden showed minimal genetic difference while $C$. oliveri from Piroche Plants (Pitt Meadows, British Columbia, Canada) had the highest genetic distance compared to $C$. harringtonia (male) from the Atlanta Botanical Garden (Atlanta, Ga.). High $\mathrm{D}_{\mathrm{xy}}$ values among established species and low $D_{x y}$ values among clones were expected. $D_{x y}$ values of varieties and cultivars were intermediate to values among species and clones.

Two UPGMA phenograms (trees) and two NJ phenograms were generated from MEGA (Sudhir et al., 1993) and NTSYS (Rohlf, 1993), respectively. Also, one consensus phenogram was generated from the phylogeny inference package (PHYLIP) (Felsenstein, 1995). Although each phenogram showed different genetic relationships among clusters, most clusters consisted of the same accessions (the detailed discussions follow). Based on 
Table 3. AFLP markers generated from three primer pairs of 90 Cephalotaxus accessions.

\begin{tabular}{|c|c|c|c|c|c|c|c|c|c|}
\hline Taxon & Blue & Green & Yellow & Total & Taxon & Blue & Green & Yellow & Total \\
\hline$\overline{01}$ & 59 & 45 & 68 & 172 & 47 & 68 & 80 & 75 & 223 \\
\hline 02 & 63 & 68 & 71 & 202 & 48 & 60 & 71 & 75 & 206 \\
\hline 03 & 69 & 77 & 77 & 223 & 49 & 61 & 74 & 73 & 208 \\
\hline 04 & 49 & 58 & 74 & 181 & 50 & 50 & 64 & 68 & 182 \\
\hline 05 & 64 & 60 & 63 & 187 & 51 & 64 & 75 & 73 & 212 \\
\hline 06 & 62 & 67 & 75 & 204 & 52 & 64 & 73 & 73 & 210 \\
\hline 07 & 67 & 63 & 71 & 201 & 53 & 64 & 78 & 70 & 212 \\
\hline 08 & 64 & 63 & 70 & 197 & 54 & 60 & 70 & 61 & 191 \\
\hline 09 & 65 & 69 & 75 & 209 & 55 & 68 & 73 & 67 & 208 \\
\hline 10 & 68 & 83 & 80 & 231 & 56 & 68 & 76 & 76 & 220 \\
\hline 11 & 70 & 72 & 77 & 219 & 57 & 49 & 75 & 76 & 200 \\
\hline 12 & 53 & 65 & 68 & 186 & 58 & 66 & 75 & 65 & 206 \\
\hline 13 & 64 & 69 & 60 & 193 & 59 & 65 & 72 & 61 & 198 \\
\hline 14 & 51 & 56 & 63 & 170 & 60 & 57 & 69 & 76 & 202 \\
\hline 15 & 40 & 69 & 74 & 183 & 61 & 58 & 66 & 72 & 196 \\
\hline 16 & 50 & 47 & 60 & 157 & 62 & 71 & 83 & 75 & 229 \\
\hline 17 & 68 & 71 & 74 & 213 & 63 & 71 & 84 & 74 & 229 \\
\hline 18 & 66 & 84 & 85 & 235 & 64 & 57 & 73 & 62 & 192 \\
\hline 19 & 69 & 71 & 80 & 220 & 65 & 71 & 78 & 70 & 219 \\
\hline 20 & 68 & 77 & 80 & 225 & 66 & 57 & 67 & 68 & 192 \\
\hline 21 & 66 & 79 & 81 & 226 & 67 & 69 & 76 & 73 & 218 \\
\hline 22 & 62 & 70 & 78 & 210 & 68 & 68 & 78 & 75 & 221 \\
\hline 23 & 69 & 79 & 71 & 219 & 69 & 58 & 76 & 67 & 201 \\
\hline 24 & 67 & 74 & 76 & 217 & 70 & 56 & 71 & 74 & 201 \\
\hline 25 & 61 & 66 & 75 & 202 & 71 & 55 & 72 & 74 & 201 \\
\hline 26 & 58 & 75 & 75 & 208 & 72 & 73 & 77 & 79 & 229 \\
\hline 27 & 62 & 74 & 76 & 212 & 73 & 59 & 71 & 68 & 198 \\
\hline 28 & 63 & 64 & 72 & 199 & 74 & 71 & 76 & 78 & 225 \\
\hline 29 & 66 & 76 & 76 & 218 & 75 & 74 & 77 & 76 & 227 \\
\hline 30 & 63 & 59 & 75 & 197 & 76 & 72 & 75 & 73 & 220 \\
\hline 31 & 68 & 68 & 76 & 212 & 77 & 39 & 74 & 78 & 191 \\
\hline 32 & 64 & 79 & 79 & 222 & 78 & 69 & 77 & 74 & 220 \\
\hline 33 & 66 & 76 & 75 & 217 & 79 & 50 & 75 & 86 & 211 \\
\hline 34 & 70 & 76 & 73 & 219 & 80 & 71 & 86 & 75 & 232 \\
\hline 35 & 68 & 73 & 80 & 221 & 81 & 70 & 81 & 79 & 230 \\
\hline 36 & 65 & 73 & 78 & 216 & 82 & 70 & 88 & 78 & 236 \\
\hline 37 & 62 & 70 & 77 & 209 & 83 & 71 & 87 & 79 & 237 \\
\hline 38 & 72 & 77 & 76 & 225 & 84 & 41 & 58 & 42 & 141 \\
\hline 39 & 59 & 75 & 77 & 211 & 85 & 65 & 81 & 66 & 212 \\
\hline 40 & 69 & 74 & 77 & 220 & 86 & 57 & 77 & 63 & 197 \\
\hline 41 & 60 & 73 & 76 & 209 & 87 & 66 & 76 & 63 & 205 \\
\hline 42 & 68 & 76 & 67 & 211 & 88 & 55 & 71 & 63 & 189 \\
\hline 43 & 47 & 67 & 59 & 173 & 89 & 54 & 69 & 44 & 167 \\
\hline 44 & 66 & 76 & 49 & 191 & 90 & 53 & 78 & 63 & 194 \\
\hline 45 & 65 & 81 & 60 & 206 & Mean & 63 & 73 & 72 & 208 \\
\hline 46 & 60 & 73 & 66 & 199 & Markers & 97 & 139 & 167 & 403 \\
\hline
\end{tabular}

the NTSYS phenograms, a consensus tree was generated with reference of MEGA phenograms and PHYLIP consensus phenogram (Fig. 1).

At the species level, the AFLP results supported the $r b c \mathrm{~L}$ gene sequence conclusions (Zhang, 1998). Cephalotaxus oliveri is a distinct species in all phenograms and showed high genetic dissimilarity (average distance $34.4 \%$ ) compared to the other taxa. Six accessions of $C$. fortune $i$ taxa were grouped as a cluster except accession 6 from Aiken, S.C.; 7 from Aiken, S.C. (natural seedling); 9 from Edinburgh Botanical Garden (687276), Scotland; 10 from F.W. Schumacher Inc., Sandwich, Mass.; and 11 from Kew Gardens (69.16245), England which were morpho- logically similar to $C$. harringtonia. Genetic differences of $<10 \%$ were observed within three U.S. accessions of $C$. fortunei species (Fig. 1). Six accessions of $C$. sinensis formed a cluster, but their genetic relationships with other taxa were confusing. The cluster was grouped either with $C$. oliveri and $C$. fortunei or with $C$. harringtonia. It is possible that $C$. sinensis is a hybrid complex (Tripp, New York Botanical Garden, personal communication). By comparing band patterns of $C$. fortunei, $C$. sinensis, and $C$. harringtonia, $C$. sinensis shared six bands with $C$. fortunei and 12 bands with $C$. harringtonia (Table 4). All three taxa shared $>80$ bands in the three primer-pair combinations (data not presented). This result supports the hypothesis that $C$. sinensis is a hybrid 


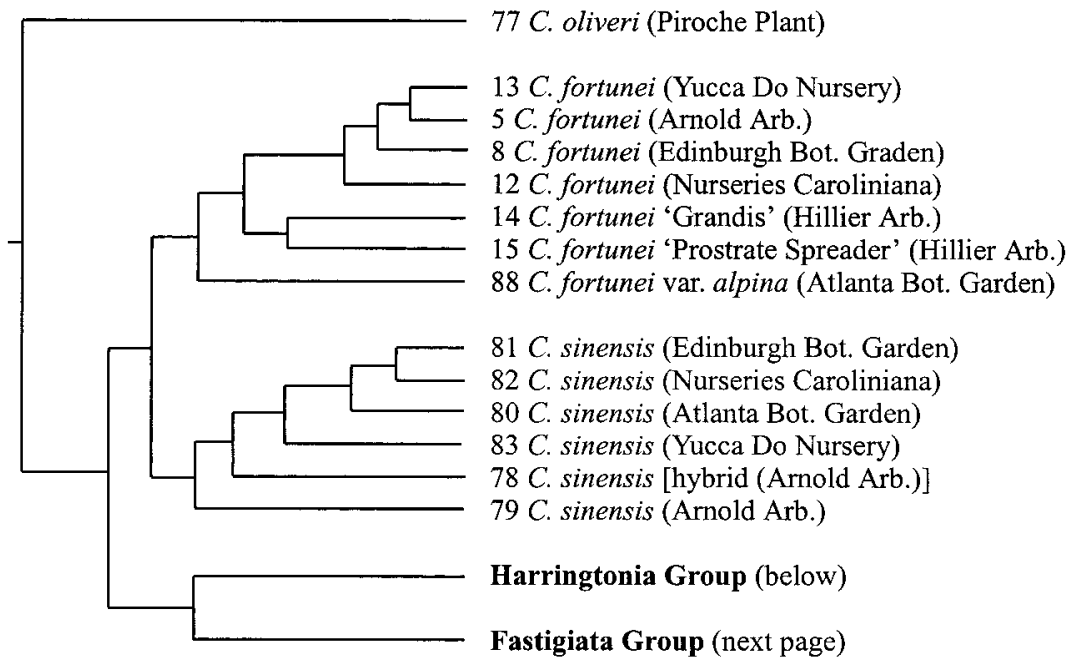

Fig. 1. Phenogram of Cephalotaxus accessions based on AFLP data. species derived from $C$. fortune $i$ and $C$. harringtonia. All other taxa (accessions) were grouped under $C$. harringtonia (Fig. 1).

The taxa subordinate to species, especially cultivars, are very important to the nursery industries. Normally, a plant with unique horticultural trait(s) can be described morphologically as a new cultivar if the trait(s) can be reproduced asexually or sexually. The plant can be patented or trademarked for protection and marketing purposes. However, no genetic information is needed for patenting or registering a new cultivar. In this study, no intraspecific taxa were available under $C$. oliveri and only two cultivars and one variety under $C$. fortunei. Cephalotaxus fortune $i$ 'Prostrate Spreader' had $16.7 \%$ genetic distance compared to C. fortunei 'Grandis' (Fig. 1). Morphologically, 'Grandis' is a female with bush-like habit and longer leaves, while 'Prostrate Spreader' originated from a side shoot (plagiotropic) and developed into a ground cover plant with widespreading branches (Hillier Nurseries, 1995). Compared with the other four accessions of $C$. fortunei, the above cultivars had at least $16.8 \%$ genetic distance. Cephalotaxus fortunei var. alpina averaged $15.2 \%$ genetic difference from the species and the above two cultivars (Fig. 1). Morphologically, the leaves of $C$. fortunei var. alpina are much wider. Based on genetic and morphological differences, the two $C$. fortunei cultivars and the variety should be accepted.

One cultivar, C. sinensis 'Dogwoodhills', was listed under $C$. sinensis. An average $26.6 \%$ genetic distance was recorded as compared to the other accessions and the lowest value of $15.0 \%$ was found compared to $C$. harringtonia from Australia in the harringtonia group. Thus, it is apparently misclassified under the wrong species. For the relationship to other taxa, it follows the same trend as its species and may be a hybrid cultivar. With only one rooted cutting available in our collection, little morphological information can be used to reach a conclusion for this taxon.

Two distinguishable groups, harringtonia and fastigiata, were separable under the species $C$. harringtonia (Fig. 1). Morphologically, the harringtonia group is characterized by uniform two-ranked leaves, upright (only terminal growth with spirally arranged leaves) or prostrate habits, while the fastigiata group bears spirally arranged or semi-whorled leaves, with leaves absent between new and old growth, leaves arranged in more or less two ranks, and columnar (no lateral branches) or vase-shaped, upright growth habits (morphological characters of $C$. koreana, $C$. harringtonia var. nana, and C. wilsoniana will be discussed later).

Fig. 1 (continued). Harringtonia Group.
1 C. drupacea (F. Pokorny's Garden)

4 C. drupacea (Ga. State Arb.)

2 C. drupacea (seedling) (F.W. Schumacher)

84 C. sinensis 'Dogwoodhills' (Yucca Do Nursery)

89 C. harringtonia (Univ. W. Australia)

90 C. harringtonia 'Sea Island' (The Cloisters)

66 C. harringtonia 'Ridge Spring' (Watson's Garden)

Four subgroups were reconciled from the harringtonia group, i.e, harringtonia, goodyear, prostrata, and drupacea (Fig. 1). The 


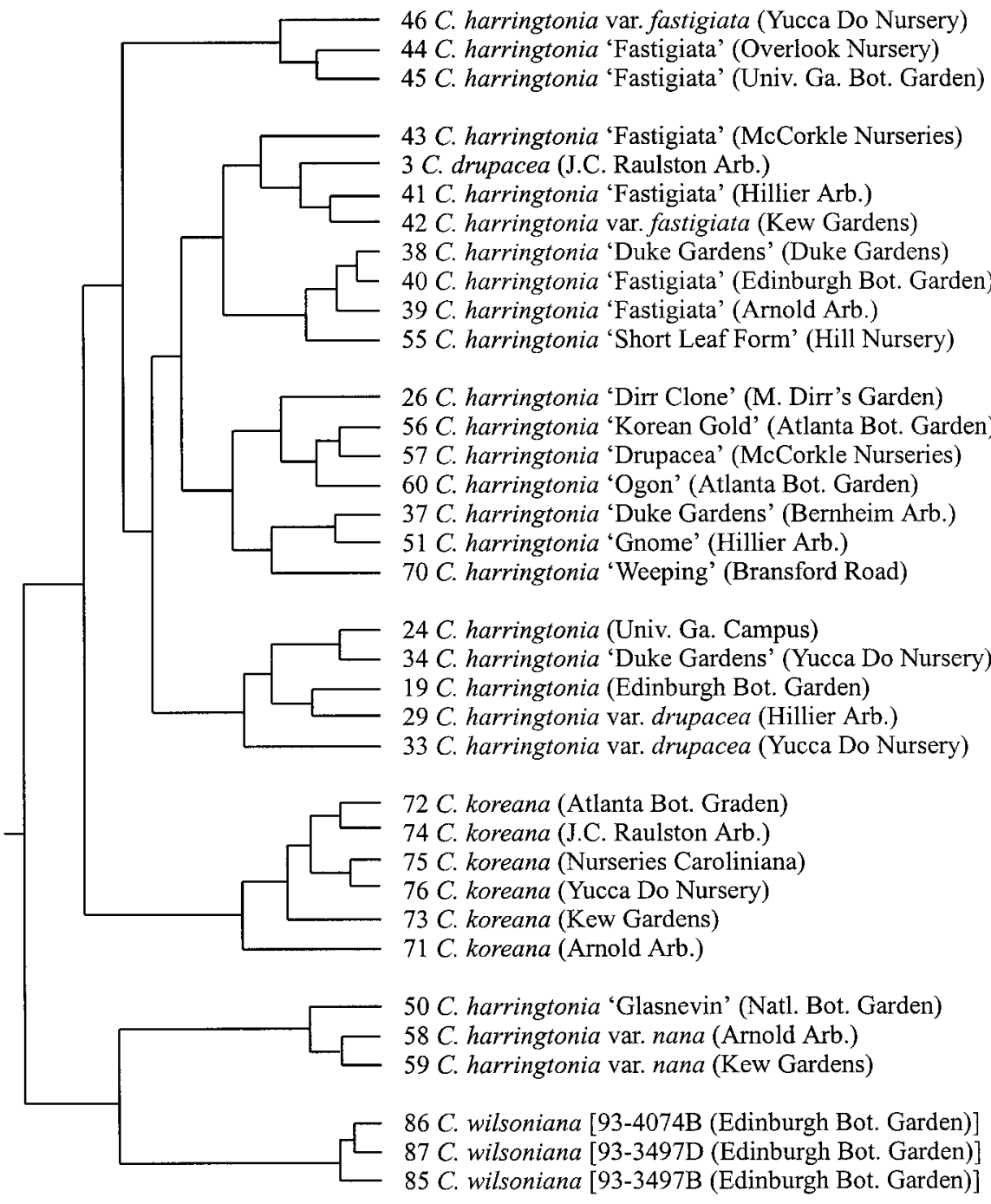

Fig. 1 (continued). Fastigiata Group.

harringtonia subgroup consisted of nine accessions in which five of them were originally named $C$. fortunei. Genetically, <14\% genetic distance was observed among accessions. Morphologically, all accessions were similar with upright or shrub-like growth habits and uniform two-ranked leaves. Accession 9, $C$. fortunei from Edinburgh Botanical Garden (687276), Scotland, and the four other accessions $(6,7,10$, and 11) were either misidentified or mislabeled. They are allied with $C$. harringtonia.

All plants in the goodyear subgroup were similar with $<10.0 \%$ genetic distance except 69 C. harringtonia 'Tall Form' from County Line Nursery, Byron, Ga. Plants developed spreading growth forms akin to ground covers. With the exception of a fast growing clone from Goodyear Garden, Aiken, S.C., C. harringtonia 'Prostrata' is the correct name for this subgroup. The prostrata subgroup had slightly over $10.0 \%$ genetic distance among accessions except 61, C. harringtonia 'Pedunculata', from the Arnold Arboretum, Jamaica Plain, Mass. Accession 35, C. harringtonia 'Mary Flemming', and 36, C. harringtonia 'Prostrate Form', (both from Yucca Do Nursery, Waller, Texas) had $5.7 \%$ genetic differences. Morphologically, the extremely recurved needles described in the Yucca Do catalog were not found on the $230-\mathrm{cm}$ tall plant that was received from the nursery. It is possible that a chimeral clonal mother plant shows different morphological characters without distinguished genetic differ- ence. However, it is logical to list both accessions as $C$. harringtonia 'Prostrata'. All other accessions had $<10.0 \%$ genetic difference while comparing with both 62 and 63, C. harringtonia 'Prostrata' (Fig. 1). Morphologically, most plants in the prostrate subgroup were prostrate or shrublike forms with dark green foliage.

Compared to the above three subgroups, the drupacea subgroup had $>20.0 \%$ genetic distance except questionable 84, C. sinensis 'Dogwoodhills', and 89, C. harringtonia. Accession 66, C. harringtonia 'Ridge Spring', was a mutation of $C$. harringtonia found by Robert McCartney in Watson's garden in Ridge Spring, S.C. The plant has an upright growth form with scalelike ( $<1 \mathrm{~cm}$ long) leaves and pendulous lateral branches. All other accessions were similar morphologically to the above three subgroups.

The fastigiata group can be also separated into four subgroups (Fig. 1). A total of 23 accessions comprised the top subgroup with $<15.0 \%$ genetic distance. Morphologically, cultivars in this subgroup did somehow relate to $C$. harringtonia 'Fastigiata' with the exception of 70, C. harringtonia 'Weeping', from Augusta, Ga.; 19, C. harringtonia, from Edinburgh Botanical Garden, Scotland; 29, C. harringtonia var. drupacea, from the Hillier Arboretum, England; and 33, C. harringtonia var. drupacea from Yucca Do Nursery, Waller, Texas. Cephalotaxus harringtonia 'Duke Gardens' is a branch sport of $C$. harringtonia 'Fastigiata' with two-ranked leaves. Cephalotaxus harringtonia 'McCorkle', a clone grown by McCorkle Nurseries, Inc., Dearing, Ga., possesses greater vigor with the V-shaped habit and semiwhorled leaves, characteristics intermediate between $C$. harringtonia 'Fastigiata' and C. harringtonia 'Duke Gardens'. Accession 51, C. harringtonia 'Gnome', from Hillier Arboretum, England is morphologically identical to C. harringtonia 'Duke Gardens'. Accessions 56 and 60, C. harringtonia 'Korean Gold' and 'Ogon' are $C$. harringtonia 'Fastigiata' with yellow new growth. All other accessions in this subgroup were probably mislabeled or misidentified. Although the genetic distances were not significantly distinguished, three morphological distinct cultivars, C. harringtonia 'Fastigiata', 'McCorkle', and 'Duke Gardens' should be accepted.

The six accessions of $C$. koreana formed a subgroup. Less than $10.0 \%$ genetic distances were observed except for $71 C$. koreana from the Arnold Arboretum, Jamaica Plain, Mass. Although plants were morphologically variable, a variety, $C$. harringtonia var. koreana, was suggested based on AFLP data. Further studies should be designed to address this question.

Cephalotaxus harringtonia 'Glasnevin' and C. harringtonia var. nana clustered together with $<15.0 \%$ genetic differences. Plants of three accessions shared compact growth habits, shining dark green foliage, needles inverted (apex pointing down) with prominent silver bands underneath. Based on genetic and morphological characteristics, a variety, C. harringtonia var. nana, should be considered.

The three accessions from three different populations of $C$. wilsoniana collected by Edinburgh Botanical Garden, Scotland, 
Table 4. Representive AFLP band patterns of C. fortunei, C. sinensis, and C. harringtonia.

\begin{tabular}{|c|c|c|c|c|c|c|c|c|}
\hline \multirow[b]{2}{*}{ Primer } & \multirow{2}{*}{$\begin{array}{l}\text { Dye } \\
\text { color }\end{array}$} & \multirow{2}{*}{$\begin{array}{l}\text { Size } \\
\text { (bp) }\end{array}$} & \multicolumn{2}{|c|}{ C. fortunei } & \multicolumn{2}{|c|}{ C. sinensis } & \multicolumn{2}{|c|}{ C. harringtonia } \\
\hline & & & $5^{z}$ & 8 & 79 & 81 & 20 & 22 \\
\hline$\overline{\mathrm{CTC}}+\mathrm{ACT}$ & Blue & 80 & - & - & - & - & - & - \\
\hline $\mathrm{CTC}+\mathrm{AGC}$ & Yellow & 113 & & & - & - & - & 一 \\
\hline $\mathrm{CTC}+\mathrm{ACG}$ & Green & 115 & - & - & - & - & & \\
\hline $\mathrm{CTC}+\mathrm{ACT}$ & Blue & 121.5 & & & - & - & - & 一 \\
\hline $\mathrm{CTC}+\mathrm{AGC}$ & Yellow & 132.5 & & & - & - & - & - \\
\hline $\mathrm{CTC}+\mathrm{ACG}$ & Green & 140 & - & - & - & - & & \\
\hline $\mathrm{CTC}+\mathrm{ACG}$ & Green & 145 & - & - & - & - & - & - \\
\hline $\mathrm{CTC}+\mathrm{AGC}$ & Yellow & 168.5 & & & - & - & - & - \\
\hline $\mathrm{CTC}+\mathrm{AGC}$ & Yellow & 178 & & & - & - & - & - \\
\hline $\mathrm{CTC}+\mathrm{AGC}$ & Yellow & 187 & - & - & - & - & & \\
\hline $\mathrm{CTC}+\mathrm{ACT}$ & Blue & 189.5 & - & - & - & - & - & 一 \\
\hline $\mathrm{CTC}+\mathrm{AGC}$ & Yellow & 189.5 & & & - & - & - & - \\
\hline $\mathrm{CTC}+\mathrm{ACG}$ & Green & 190 & & & - & - & - & 一 \\
\hline $\mathrm{CTC}+\mathrm{AGC}$ & Yellow & 204 & & & - & - & - & - \\
\hline $\mathrm{CTC}+\mathrm{AGC}$ & Yellow & 221 & & & - & - & - & 一 \\
\hline $\mathrm{CTC}+\mathrm{AGC}$ & Yellow & 223.5 & - & - & - & - & & \\
\hline $\mathrm{CTC}+\mathrm{AGC}$ & Yellow & 238 & & & - & - & - & - \\
\hline $\mathrm{CTC}+\mathrm{ACT}$ & Blue & 281 & - & - & - & - & & \\
\hline $\mathrm{CTC}+\mathrm{ACG}$ & Green & 297 & & & - & - & - & - \\
\hline $\mathrm{CTC}+\mathrm{AGC}$ & Yellow & 297 & - & - & - & - & & \\
\hline $\mathrm{CTC}+\mathrm{AGC}$ & Yellow & 383.5 & & & - & - & - & - \\
\hline $\mathrm{CTC}+\mathrm{ACG}$ & Green & 450.5 & - & - & - & - & - & - \\
\hline
\end{tabular}

${ }^{\mathrm{z}}$ Accession number in Table 1.

were included in this study. Regardless of the clustering methods (UPGMA or NJ) and programs (NTSYS, MEGA, and PHYLIP), the three accessions always formed a subgroup. Less than $10.0 \%$ genetic difference was recorded. Literature descriptions and molecular data (Cheng and Fu, 1978; Fu, 1984; Zhang, 1998) indicated that the variety $C$. harringtonia var. wilsoniana should be accepted.

The large number of fragments amplified from the Cephalotaxus genome shows the potential of the AFLP technique for cultivar discrimination and genetic analyses. Sharma et al. (1996) reported that the AFLP method detected 10 times more informative bands per primer than the RAPD method with Lens. Also reproducibility and reliability of the AFLP technique had been reported as being very high (Janssen et al., 1996; Vos et al., 1995; Zabeau and Vos, 1993), especially when the semiautomated fluorescence-based AFLP method was used (Zhang, 1997). In this preliminary study, the genetic differences among 90 Cephalotaxus accessions are documented (data not presented). For cultivar discrimination, 90 accessions could be distinguished as four species, four varieties, and eight cultivars (Table 1).

The origin of Cephalotaxus is complicated, particularly for the cultivated taxa (Dirr, 1990; Tripp, 1994). Different relationships occurred if the AFLP data were analyzed using different cluster methods and different computer programs. Since Cephalotaxus was introduced to cultivation, plants from different geographical regions in the world have been collected and cultivated in the same area. Hybridization has possibly occurred among Cephalotaxus taxa. If so, it is impossible to determine the relationships among Cephalotaxus taxa with this AFLP data.

Although the clustering results varied using different methods, some accessions were $100 \%$ associated within a formed single subgroup. The three accessions of $C$. wilsoniana provide a good example, which also indicated that the AFLP method can be used for investigating genetic diversity among Cephalotaxus populations.
Morphological changes may not follow the same trend as the genetic changes because morphological characteristics may be regulated by environmental factors. Also, some genetic changes might not be reflected by morphological characteristics. In this study, three cultivars in the harringtonia group can be explained by these factors. If the dark green short needles or yellow new growth are considered stable morphological characteristics, then C. harringtonia 'Fritz Huber' or 'Korean Gold', respectively, should be accepted. In nursery production, most Cephalotaxus are propagated by stem cuttings. Topophysis is another factor determining the growth habits of the rooted cuttings (Dirr and Heuser, 1987). Prostrate growing plants can be rooted from the horizontal branches (plagiotropic) while upright plants result from rooting cuttings from vertical (orthotropic) branches. If both types of cuttings were collected from a single plant, two or more growth forms can be produced without any genetic difference. Although AFLP is a highly informative method, it would be virtually impossible to detect such genetic differences.

\section{Conclusion}

Based on results of AFLP data combined with morphological characteristics, three species, $C$. oliveri, $C$. fortunei, and $C$. harringtonia, and one hybrid species, $C$. $\times$ sinensis, four varieties, C. fortune i var. alpina, $C$. harringtonia var. koreana, C. harringtonia var. nana, and C. harringtonia var. wilsoniana, and eight cultivars, C. fortunei 'Grandis' and 'Prostrate Spreader', C. harringtonia 'Duke Gardens', 'Fastigiata', 'Goodyear', 'McCorkle', 'Prostrata', and 'Ridge Spring' should be accepted. The data in this study serve as a guide to researchers and growers for identification and genetic distance and a model to establish a cultivar library against which later introductions or nomenclatural irregularities within Cephalotaxus can be cross-referenced. 


\section{Literature Cited}

Becker, J., P. Vos, M. Kuiper, F. Salamini, and M. Heun. 1995. Combined mapping of AFLP and RFLP markers in barley. Mol. Gen. Genet. 249:65-73.

Cheng, W.C. and L.K. Fu. 1978. Flora reipublicae popularis sinicae, Tomus 7 (Gymnospermae). Science Press, Beijing, People's Republic of China.

Dallimore, W. and A.B. Jackson. 1967. A handbook of Coniferae and Ginkgoaceae. St. Martin's Press, New York.

Dirr, M.A. 1990. Manual of woody landscape plants: Their identification, ornamental characteristics, culture, propagation, and uses. Stipes Publishing Co., Champaign, Ill.

Dirr, M.A. 1992. Cephalotaxus harringtonia, the Japanese plum yew: Superbly tolerant of heat, drought, sun, and cold dipping to $-15^{\circ}$ to $20^{\circ}$. Nursery Manager 8(4):24-25.

Dirr, M.A. and C.W. Heuser, Jr. 1987. The reference manual of woody plant propagation: From seed to tissue culture. Varsity Press, Athens, Ga.

Elder, J.K. and E.M. Southern. 1987. Computer-aid analysis of onedimensional restriction fragment gels, p. 165-175. In: M.J. Bishop and J. Rawlings (eds.). Nucleic acid and protein sequence analysis-A practice approach. IRL Press, Oxford, U.K.

Felsenstein, J. 1995. PHYLIP (Phylogeny inference package) Version 3.57c. Univ. Wash., Seattle (http://evolution.genetics.washington.edu/ phylip.html).

Fu, L.K. 1984. A study on the genus Cephalotaxus Sieb. et Zucc. Acta Phytotaxon Sin. 24:277-288.

Guillemaut, P. and L. Marechal-Drouard. 1992. Isolation of plant DNA: A fast, inexpensive, and reliable method. Plant Mol. Biol. Rpt. 10:60-65.

Harlass, S. 1994. Georgia names 4 outstanding plants. Greenhouse Mgr. 13(1):79-82.

Hillier Nurseries. 1995. The Hillier manual of trees and shrubs. David and Charles, Inc., North Pomfret, Vt.

Hubbard, M., J. Kelly, S. Rajapakse, A. Abbott, and R. Ballard. 1992. Restriction fragment length polymorphisms in rose and their use for cultivar identification. HortScience 27:172-173.

Janssen, P., R. Coopman, G. Huys, J. Swings, M. Bleeker, P. Vos, M. Zabeau, and K. Kersters. 1996. Evaluation of DNA fingerprinting method AFLP as a new tool in bacterial taxonomy. Microbiology 142:1881-1893.

Kamalay, J.C. and D.W. Carey. 1995. Application of RAPD-PCR markers for identification and genetic analysis of american elm (Ulmus americana L.) selections. J. Environ. Hort. 13:155-159.

Krahl, K.H., M.A. Dirr, T.M. Halward, G.D. Kochert, and W.M. Randle. 1993. Use of single-primer DNA amplification for the identification of red maple (Acer rubrum L.) cultivars. J. Environ. Hort. 11:89-92.

Krüssmann, G. 1985. Manual of cultivated conifers. Timber Press, Portland, Ore.

Lin, J.J., J. Kuo, J. Ma, J.A. Saunders, H.S. Beard, M.H. MacDonald, W. Kenworthy, G.N. Ude, and B.F. Mathews. 1996. Identification of molecular markers in soybean comparing RFLP, RAPD and AFLP mapping techniques. Plant Mol. Biol. Rpt. 14:156-169.

Mabberly, D.J. 1993. The plant-book. Cambridge Univ. Press, Cambridge, U.K.
Meksem, K., D. Leister, J. Peleman, M. Zabeau, F. Salamini, and C. Gebhardt. 1995. A high resolution map of the vicinity of the R1 locus on chromosome $\mathrm{V}$ of potato based on RFLP and AFLP markers. Mol. Gen. Genet. 249:74-81.

Michelmore, R.W., I. Paran, and R.V. Kesseli. 1991. Identification of markers linked to disease resistance genes by bulked segregant analysis: A rapid method to detect markers in specified genomic regions using segregating populations. Proc. Natl. Acad. Sci. USA 88:98289832 .

Miller, J.C. and S.D. Tanksley. 1990. RFLP analysis of phylogenetic relationships and genetic variation in the genus Lycopersicon. Theor. Appl. Genet. 80:437-448.

Nei, M. and W.H. Li. 1979. Mathematical model for studying genetic variation in terms of restriction endonuclease. Proc. Natl. Acad. Sci. USA 76:5269-5273.

Nybom, H. 1994. DNA fingerprinting-A useful tool in fruit breeding. Euphytica 77:59-64.

Paul, S., F.N. Wachira, W. Powell, and R. Waugh. 1997. Diversity and genetic differentiation among populations of Indian and Kenyan tea [(Camellia sinensis (L.) O. Kuntze] revealed by AFLP markers. Theor. Appl. Genet. 94:255-263.

PE Applied Biosystems. 1996. AFLP plant mapping protocol. PerkinElmer Corp., Foster City, Calif.

Rohlf, F. J. 1993. NTSYS: Numerical taxonomy and multivariate analysis system (version 1.80). State Univ. N.Y., Stony Brook.

Rushforth, K.D. 1987. Conifers. Christopher Helm Publishers, Ltd., London.

Sharma, S.K., M.R. Knox, and T.H.N. Ellis. 1996. AFLP analysis of the diversity and phylogeny of Lens and its comparison with RAPD analysis. Theor. Appl. Genet. 93:751-758.

Silba, J. 1984. Phytologia memoirs VII: An international census of the Coniferae, I. Moldenke Publisher, Plainfield, N.J.

Staub, J.E. and V. Meglic. 1993. Molecular genetic markers and their legal relevance for cultivar discrimination: A case study in cucumber. HortTechnology 3:291-300.

Sudhir K., K. Tamura, and M. Nei. 1993. MEGA: Molecular evolutionary genetics analysis (version 1.01). Pa. State Univ., Univ. Park, Pa.

Tripp, K. 1994. A plum yew primer. American Nurseryman 180(9):2837.

Vos, P., R. Hogers, M. Bleeker, M. Reijans, T. van de Lee, M. Hornes, A. Frijters, J. Pot, J. Peleman, M. Kuiper, and M. Zabeau. 1995. AFLP: A new technique for DNA fingerprinting. Nucleic Acids Res. 23:44074414.

Wang, Z.Y., G. Second, and S.D. Tanksley. 1992. Polymorphism and phylogenetic relationships among species in the genus Oryza as determined by analysis of nuclear RFLPs. Theor Appl. Genet. 83:565-581.

Zabeau, M. and P. Vos. 1993. Selective restriction fragment amplification: A general method for DNA fingerprinting. European Patent Application No. 92402629.7.

Zhang, D. 1998. Classification of Cephalotaxus species based on $r b c \mathrm{~L}$ sequences. PhD diss., Univ. Georgia, Athens.

Zhang, L. 1997. Genotype identification of bermudagrass (Cydonon spp.) by AFLP analysis. MS thesis, Univ. Georgia, Athens. 